\title{
Case of spontaneous regression of carotid body tumor in a SDHD mutant: a discussion on potential mechanisms based on a review of the literature
}

Sebastiaan Hammer ${ }^{1 *}$, Jeroen C Jansen ${ }^{2}$, Eleonora PM van der Kleij-Corssmit ${ }^{3}$, Frederik J Hes ${ }^{4}$ and Mark C Kruit ${ }^{1}$

\begin{abstract}
Background: Head and neck paragangliomas are tumors associated with the parasympathetic nerve system and typically show an indolent growth pattern. Therefore a conservative management strategy is considered in selected cases.

Methods and results: We present a case of a female patient who presented in 2003 with bilateral carotid body tumors and a tympanic tumor, associated with a mutation in the succinate dehydrogenase -sub-unit-D (SDHD). She was operated on the right carotid body tumor and the tympanic tumor. Thereafter the follow-up was performed with MR examinations at 2-year intervals. After an initial stable phase, over the last 3 years a spontaneous near-total regression of the contralateral carotid body tumor was observed, with only subtle rest-abnormalities visible in 2011.

Conclusions: The present case underlines the indolent growth pattern of head and neck paragangliomas and for the first time describes a rare manifestation of spontaneous regression of a carotid body tumor. The literature was reviewed to discuss this phenomenon.
\end{abstract}

Keywords: Tumor regression, Head and neck paragangliomas, Spontaneous involution, Surgical resection

\section{Background}

Head and neck paragangliomas (HNPGL) are usually benign, slow-growing tumors associated with the parasympathetic nerve system. Common sites include the carotid body, the temporal bone, and the vagal body [1]. The majority of patients presents as apparently sporadic patients, whereas $10 \%$ to $20 \%$ of patients report a positive family history $[2,3]$. Multiple paragangliomas may occur in up to $40 \%$ of patients [4]. In the Netherlands the majority of cases are related to mutations in the gene encoding for the oxidative chain protein succinate dehydrogenase-sub-unit-D (SDHD) [5]. In the neck, a paraganglioma presents as a non-tender mass or as a cause of lower cranial nerve palsy due to local compression. In the temporal bone, the first symptom of paragangliomas is

\footnotetext{
* Correspondence: S.Hammer@lumc.nl

1Departments of Radiology, Leiden University Medical Center, Albinusdreef 2, Leiden, ZA 2333, The Netherlands

Full list of author information is available at the end of the article
}

usually pulsating tinnitus, due to the hypervascular nature of the tumor. In follow-up about $60 \%$ of the HNPGL do not exhibit growth, and if they do it typically is in an indolent growth pattern with a median tumor double time of 4.2 years [6]. Diagnosis is generally made through a combination of clinical findings and magnetic resonance imaging (MRI) studies. Treatment considerations include the nature of the tumor (malignant or benign), the location, vasculature encasement, the extent, and growth rate $[6,7]$. Treatment modalities include surgery or radiotherapy/surgery; treatment of choice for carotid body tumors is surgical resection. However, because of the slow growth rate and potential treatment-related injury to the neighboring vessels and nerves, a conservative management strategy (wait-and-scan policy) should be considered [6].

\section{Case presentation}

In 2003 a 32-year-old female patient was referred to our institution after magnetic resonance imaging (MRI)

\section{Biomed Central}






Figure 1 Transverse gadolinium-enhanced 3D time of flight magnetic resonance angiography images at baseline in 2004 show the bilateral carotid body tumors (arrows).

examination in a regional hospital had revealed bilateral carotid body tumors. She had discovered a swelling in the right neck since 6 months before, and only after questioning mentioned a long-existing pulsatile tinnitus on the right side. The family history for paragangliomas was positive: her father and uncle were affected.

Physical examination revealed a small reddish tumor in the right middle ear, with positive Brown's sign and a tumor in the right neck at the level of the hyoid bone; on the left side there was no palpable lesion. The lower cranial nerves were intact and the hearing was normal. In general examination, the patient was all-over obese (weight $121 \mathrm{~kg}$, length $1.75 \mathrm{~m}$, body mass index 39.5), blood pressure was $130 / 70 \mathrm{~mm} \mathrm{Hg}$, pulse rate $80 / \mathrm{min}$. There were no other abnormalities. Urinary excretion (24-h sample) of catecholamines was repeatedly normal.
Germline mutation analysis in DNA from a blood sample demonstrated a mutation in SDHD (P-Asp92Tyr).

MRI including a gadolinium-enhanced 3D time-offlight MR angiography sequence [8] was acquired at our institution in April 2004, and revealed hypervascular enhancing lesions in the carotid bifurcation bilaterally, consistent with carotid body tumors. The maximum transverse diameter was $23 \mathrm{~mm}$ on the right and $12 \mathrm{~mm}$ on the left (Figure 1). A tympanic tumor was identified on the right side.

The right carotid body tumor was surgically resected in 2004, followed by extirpation of the tympanic tumor in 2005. No radiotherapy was applied. There were no complications from the surgical procedures. In the postoperative phase a severe obstructive sleep apnea syndrome (OSAS) was diagnosed, for which she started continuous positive airway pressure (CPAP) therapy. In 2005 she started thyroid hormone suppletion for Hashimoto disease. Between 2005 and 2008, the patient intentionally lost weight from $136 \mathrm{~kg}$ to $93 \mathrm{~kg}$, because of a pregnancy wish which was eventually unsuccessful. During follow-up the patient regained bodyweight in 2010 to $129 \mathrm{~kg}$. In 2011 she suffered anamnestically from a transient ischemic attack (with no abnormalities on imaging studies), after which she started statin treatment and therapy with carbaselate calcium and dipyridamole.

Follow-up MRI was performed with 2-year intervals (Figure 2), and showed no evidence of recurrence on the operated sites. Between 2004 and 2008 there were no changes in size and enhancement pattern of the left carotid body tumor and therefore surgical resection was considered unnecessary. Unexpectedly, in 2010, the tumor was significantly smaller, and showed reduced enhancement in the center of the lesion, consistent with necrosis. Follow-up examinations in June 2011 and September 2011 showed nearly complete regression,
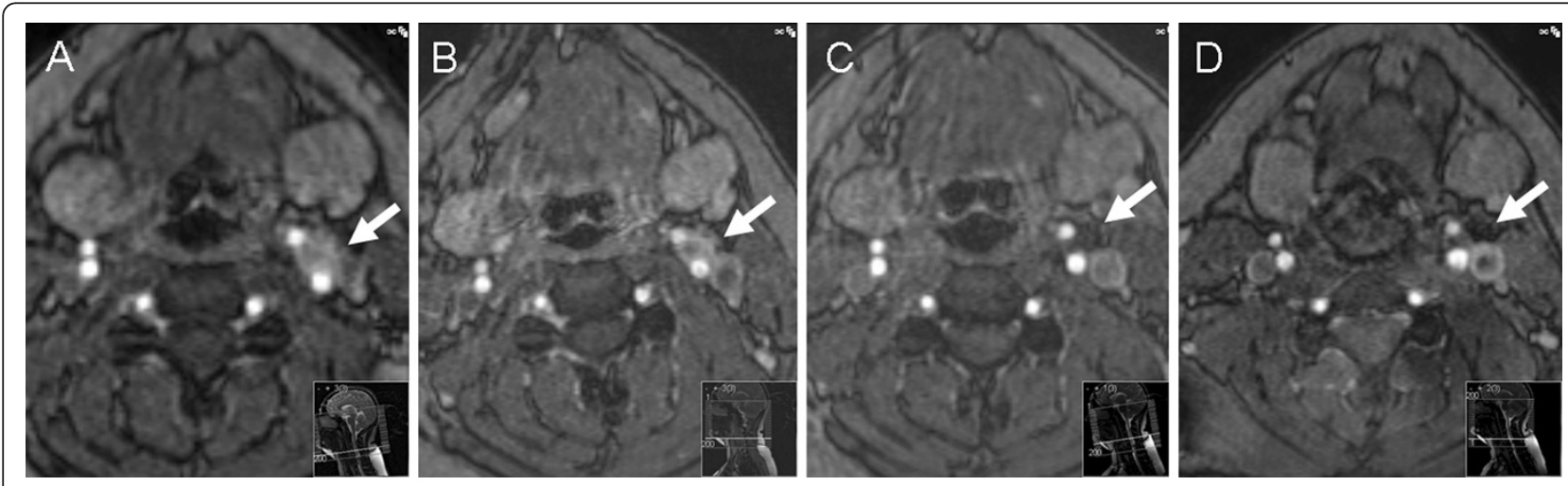

Figure 2 Transverse gadolinium-enhanced 3D time-of-flight magnetic resonance angiography images at subsequent intervals showing the carotid body tumor on the left in 2006 (A), unchanged in 2008 (B), inhomogeneous ring-like enhancement in 2010 (C), and further regression in 2011 (D). On the image only a subtle linear enhancement is noted, no evidence of an enhancing mass could be detected. 
leaving only minimal rest-abnormalities at the site of the previous tumor. Other affected family members showed no signs of regression during follow-up.

\section{Discussion}

We describe a patient with hereditary bilateral head and neck paragangliomas who underwent surgical tumor removal of a right carotid body tumor and a right tympanic tumor. During the 7-year follow-up, spontaneous regression of the left carotid body tumor was noted, after an initial period without any change in tumor size. To the best of our knowledge, spontaneous involution of head and neck paragangliomas has not been reported before. In our referral center for paragangliomas, the present case with spontaneous involution represents the first from an estimated total of more than 400 followed cases.

Spontaneous regression of tumors in general is a rare phenomenon, although numerous cases and case series can be found in the literature. Spontaneous remission of tumors with a common neural crest embryological origin as paragangliomas has been described as well. Regression of pheochromocytomas after initial presentation with hypertensive crises or shock has been reported [9-11], as well as spontaneous regression [12], Another known entity is spontaneous regression in a subset of pediatric neuroblastomas, especially those detected with mass screening and with biologically favorable characteristics $[13,14]$.

\section{Mechanism}

The mechanism that accounts for the regression in the present case can only be speculated upon. Below we discuss the general tumor regression hypotheses, including biological (genetic, immunological), hormonal (such as contraceptive use), vascular (vascular insufficiency/tumor necrosis/spontaneous intratumoral vascular thrombosis), and operative mechanisms [15].

Biological mechanisms related to tumor regression include genetic instability (telomerase inhibition) and programmed cell death, which has been described for neuroblastomas [16,17]. The specific SDHD mutation in the present case (p.Asp92Tyr), however, is relatively common - as it is found in almost 70\% of 690 Dutch SDHgene mutation carriers [5] and has not been reported to be associated with spontaneous tumor regression before.

Although changes in body weight may go with changes in catecholamine levels, we found no evidence for such changes in our patient, neither after the start of CPAP treatment for OSAS. Therefore a hormonal mechanism for tumor regression seems unlikely.

Vascular mechanisms may be due to changes in tumor angiostructure, and have been reported in spontaneous regressed (biologically favorable) neuroblastomas [18]. Such vascular mechanism could have explained the regression in the present case, although we have no supportive biomarkers for this hypothesis.

Operative mechanisms include regression of a tumor after biopsy, which has been described in patients with Merkel cell tumors $[19,20]$, and involution of metastases after resection of a primary tumor, recently described in a patient with lung metastases of hepatocellular carcinoma [21]. Another example comes from a patient with three hemangioblastomas (not related to Von HippelLindau disease), of which two regressed completely 6 months after surgical resection of the first tumor [22]. The authors hypothesized that the resected tumor may have been supportive for the existence of the other two. Furthermore, in two patients with neurofibromatosis type 2 and bilateral vestibular schwannomas, spontaneous regression after resection of the contralateral tumor was reported [23]. In this paper, one patient showed an initial increase in tumor size, directly after resection of the contralateral schwannoma. Afterwards, a gradual decrease in tumor size was objectified from 6 months postoperatively. Tumor size increased initially in the second patient as well, whereas a decrease in tumor size was noted from approximately 60 months [23]. A similar mechanism may explain the regression of the left carotid body tumor after initial resection of the carotid body tumor on the right in our case.

Although the present case describes spontaneous involution, surgical resection is the favored treatment in carotid body tumors. Nevertheless, resection is associated with complications such as cranial nerve impairment, stroke, or partial scarification of the carotid arteries [24].

\section{Conclusions}

In conclusion, the present case underlines the indolent growth pattern of head and neck paragangliomas and for the first time describes a rare manifestation of involution of a carotid body tumor.

\section{Consent}

Written informed consent was obtained from the patient for publication of this case report and any accompanying images. A copy of the written consent is available for review by the Editor-in-Chief of this journal.

\section{Abbreviations \\ CPAP: Continuous positive airway pressure; HNPGL: Head and neck paragangliomas; MRI: Magnetic resonance imaging; OSAS: Obstructive sleep apnea syndrome; SDHD: Succinate dehydrogenase-sub-unit-D. \\ Competing interest \\ All authors declare no competing interest.}

\section{Authors' contributions}

$\mathrm{SH}$ and MK carried out the MR examinations and drafted the manuscript. FH performed genetic analysis and drafted the manuscript. JJ and EC performed 
physical examinations and patient follow-up and drafted the manuscript. All authors read and approved the final manuscript.

\section{Author details}

'Departments of Radiology, Leiden University Medical Center, Albinusdreef 2, Leiden, ZA 2333, The Netherlands. ${ }^{2}$ Departments of Head and Neck Surgery, Leiden University Medical Center, Albinusdreef 2, Leiden, ZA 2333, The Netherlands. ${ }^{3}$ Departments of Endocrinology, Leiden University Medical Center, Albinusdreef 2, Leiden, ZA 2333, The Netherlands. ${ }^{4}$ Departments of Human and Clinical Genetics, Leiden University Medical Center, Albinusdreef 2, Leiden, ZA 2333, The Netherlands.

Received: 7 August 2012 Accepted: 14 October 2012 Published: 19 October 2012

\section{References}

1. Pellitteri PK, Rinaldo A, Myssiorek D, Gary JC, Bradley PJ, Devaney KO, Shaha AR, Netterville JL, Manni JJ, Ferlito A (2004) Paragangliomas of the head and neck. Oral Oncol 40:563-575

2. Burnichon $N$, Vescovo $L$, Amar $L$, Libe $R$, deReynies $A$, Venisse $A$, Jouanno $E$, Laurendeau I, Parfait B, Bertherat J, Plouin PF, Jeunemaitre X, Favier J, Gimenez-Roqueplo AP (2011) Integrative genomic analysis reveals somatic mutations in pheochromocytoma and paraganglioma. Hum Mol Genet 20:3974-3985

3. Gimenez-Roqueplo AP, Burnichon N, Amar L, Favier J, Jeunemaitre X, Plouin PF (2008) Recent advances in the genetics of phaeochromocytoma and functional paraganglioma. Clin Exp Pharmacol Physiol 35:376-379

4. Bikhazi PH, Roeder E, Attaie A, Lalwani AK (1999) Familial paragangliomas: the emerging impact of molecular genetics on evaluation and management. Am J Otol 20:639-643

5. Hensen EF, Siemers MD, Jansen JC, Corssmit EP, Romijn JA, Tops CM, van der Mey AG, Devilee P, Cornelisse CJ, Bayley JP, Vriends AH (2011) Mutations in SDHD are the major determinants of the clinical characteristics of Dutch head and neck paraganglioma patients. Clin Endocrinol (Oxf) 75:650-655

6. Jansen JC, van den Berg R, Kuiper A, van der Mey AG, Zwinderman AH, Cornelisse CJ (2000) Estimation of growth rate in patients with head and neck paragangliomas influences the treatment proposal. Cancer 88:2811-2816

7. Mendenhall WM, Amdur RJ, Vaysberg M, Mendenhall CM, Werning JW (2011) Head and neck paragangliomas. Head Neck 33:1530-1534

8. van den Berg R, Verbist BM, Mertens BJ, van der Mey AG, van Buchem MA (2004) Head and neck paragangliomas: improved tumor detection using contrast-enhanced 3D time-of-flight MR angiography as compared with fat-suppressed MR imaging techniques. AJNR Am J Neuroradiol 25:863-870

9. Delaney JP, Paritzky AZ (1969) Necrosis of a pheochromocytoma with shock. N Engl J Med 280:1394-1395

10. Terai A, Terachi T, Yoshida S, Kadota K (1989) Pheochromocytoma presenting as shock and followed by spontaneous remission. Urol Int 44:58-60

11. Suzuki T, Mori C, Asakage H, Akaza H, Kawabe K, Ueno A, Koiso K, Niijima T (1984) Pheochromocytoma with remission following phentolamine-induced shock. Urology 23:582-584

12. Zanin L, Rossi G, Poletti A, Piotto A, Chiesura-Corona M, Pessina AC (1993) Necrosis of a phaeochromocytoma associated with spontaneous remission of diabetes and hypertension. Clin Endocrinol (Oxf) 39:613-617

13. Maris JM, Hogarty MD, Bagatell R, Cohn SL (2007) Neuroblastoma. Lancet 369:2106-2120

14. Yamamoto K, Hanada R, Kikuchi A, Ichikawa M, Aihara T, Oguma E, Moritani T, Shimanuki Y, Tanimura M, Hayashi Y (1998) Spontaneous regression of localized neuroblastoma detected by mass screening. J Clin Oncol 16:1265-1269

15. Challis GB, Stam HJ (1990) The spontaneous regression of cancer. A review of cases from 1900 to 1987. Acta Oncol 29:545-550

16. Kim NW (1997) Clinical implications of telomerase in cancer. Eur J Cancer 33:781-786

17. Nakagawara A, Nakamura Y, Ikeda H, Hiwasa T, Kuida K, Su MS, Zhao H, Cnaan A, Sakiyama S (1997) High levels of expression and nuclear localization of interleukin-1 beta converting enzyme (ICE) and CPP32 in favorable human neuroblastomas. Cancer Res 57:4578-4584
18. Eggert A, Grotzer MA, Ikegaki N, Liu XG, Evans AE, Brodeur GM (2002) Expression of the neurotrophin receptor TrkA down-regulates expression and function of angiogenic stimulators in SH-SY5Y neuroblastoma cells. Cancer Res 62:1802-1808

19. Val-Bernal JF, Garcia-Castano A, Garcia-Barredo R, Landeras R, De JA, Garijo MF (2011) Spontaneous complete regression in merkel cell carcinoma after biopsy. Adv Anat Pathol 18:174-177

20. Yagi Y, Fujisawa A, Makiura M, Morita K (2009) Spontaneous regression of Merkel cell carcinoma after biopsy. J Dermatol 36:312-313

21. Harimoto N, Shirabe K, Kajiyama K, Gion T, Takenaka M, Nagaie T, Maehara Y (2012) Spontaneous regression of multiple pulmonary recurrences of hepatocellular carcinoma after hepatectomy: report of a case. Surg Today 42:475-478

22. Lindvall P, Brannstrom T (2008) Spontaneous regression of two putative supratentorial haemangioblastomas in one patient. Acta Neurochir (Wien ) 150:73-76

23. von Eckardstein KL, Beatty CW, Driscoll CL, Link MJ (2010) Spontaneous regression of vestibular schwannomas after resection of contralateral tumor in neurofibromatosis Type 2. J Neurosurg 112:158-162

24. Lim JY, Kim J, Kim SH, Lee S, Lim YC, Kim JW, Choi EC (2010) Surgical treatment of carotid body paragangliomas: outcomes and complications according to the shamblin classification. Clin Exp Otorhinolaryngol 3:91-95

doi:10.1186/1477-7819-10-218

Cite this article as: Hammer et al:: Case of spontaneous regression of carotid body tumor in a SDHD mutant: a discussion on potential mechanisms based on a review of the literature. World Journal of Surgical Oncology 2012 10:218.

\section{Submit your next manuscript to BioMed Central and take full advantage of:}

- Convenient online submission

- Thorough peer review

- No space constraints or color figure charges

- Immediate publication on acceptance

- Inclusion in PubMed, CAS, Scopus and Google Scholar

- Research which is freely available for redistribution 